Article

\title{
Fabrication and Characterization of Modified Graphene Oxide/PAN Hybrid Nanofiber Membrane
}

\author{
Jian Hou 1,2 ${ }^{1}$, Jaehan Yun ${ }^{2}$ and Hongsik Byun ${ }^{2, *}$ \\ 1 Department of Chemical Engineering, Zibo Vocational Institute, Zibo 255314, China; houjimmy@naver.com \\ 2 Department of Chemical Engineering, Keimyung University, Daegu 704701, Korea; ruri7220@naver.com \\ * Correspondence: hsbyun@kmu.ac.kr; Tel.: +82-53-580-5569
}

Received: 29 July 2019; Accepted: 17 September 2019; Published: 19 September 2019

check for updates

\begin{abstract}
In this study, a series of novel modified graphene oxide (MGO)/polyacrylonitrile (PAN) hybrid nanofiber membranes were fabricated by electrospinning a PAN solution containing up to $1.0 \mathrm{wt}$ \% MGO. The GO was initially prepared by a time-saving improved Hummer's method. Subsequently, the formation of GO was confirmed by scanning electron microscopy (SEM), AFM, Fourier-transform infrared spectroscopy (FT-IR), and Raman spectroscopy. This study also prepared the modified GO with polydiallyldimethylammonium chloride (GP) by using a simple surface post-treatment method to improve its dispersion. Varying amounts of GP were incorporated into PAN nanofibers for the better properties of GP/PAN nanofibers, such as hydrophilicity, mechanical properties, and so on. The resulting GP/PAN hybrid nanofiber membranes were characterized by SEM, FTIR, contact angle, and thermal and mechanical properties. These results showed that the hydrophilic and mechanical properties of GP/PAN hybrid nanofiber membranes were dramatically improved, i.e., 50\% improvement for hydrophilicity and 3-4 times higher strength for mechanical property, which indicated the possibility for water treatment application. In addition, the notably improved thermal stability results showed that the hybrid nanofiber membranes could also be a potential candidate for the secondary battery separator.
\end{abstract}

Keywords: modified GO; PAN; hybrid nanofiber membrane; polydiallyldimethylammonium chloride (PDDA)

\section{Introduction}

Nanofibers, which are important nanomaterials, have attracted increasing attention over the last two decades. A nanofiber generally refers to a fiber having a diameter less than $100 \mathrm{~nm}$. However, fibers with diameters less than $1000 \mathrm{~nm}$ (micro-) can also be defined as nanofibers in the fiber industry field [1,2]. Many researches on the fabrication and application of nanofibers have attracted great interest from both academia and industry. The general fabricating methods of nanofibers are electrospinning, self-assembly, phase separation, melting blown, and nanoporous template. Among these methods, electrospinning is the most promising method for producing continuous nanofibers on a large scale, and the fiber diameter can be easily adjusted. Also, electrospinning is a relatively simple and fast process to produce nanofibers [3-6]. A number of organic polymers, including natural and biomaterial polymers, have been successfully spun into nanofibers using electrospinning. Electrospun nanofibers have many applications due to their excellent properties, such as very small pores, large surface area, and higher porosity compared with regular fibers, which are produced by conventional melt and wet spinning processes [7-9]. Until now, nanofibers have been widely reported and applied in various fields, such as filtrations, wound dressings, tissue engineering scaffolds, protective clothing, electronics, sensors, energy storage, and drug delivery materials. Other new applications have been continuously explored for these nanofibers [10-13]. 
Recent researches have shown that polyacrylonitrile (PAN) was generally chosen to prepare nanofiber membranes and used as a water treatment membrane or Li-ion battery (LIB) separator [14,15]. Firstly, PAN is one of the most extensively used polymers in electrospinning because of its excellent properties [16,17]. Furthermore, electrospun PAN nanofibers possess a variety of advantages, including thermal stability, resistance to most solvents, high strength, and so on [18,19]. In addition, in order to further improve the hydrophilicity and other properties of PAN nanofibers, some nanofillers such as nanosized $\mathrm{TiO}_{2}, \mathrm{ZnO}$, graphene oxide (GO), etc. have been added to the polymer solution to prepare hybrid nanofibers [20-22]. Instead, GO contains several oxygen-containing groups, such as epoxy and hydroxyl groups at basal plane and carbonyl and carboxylic groups at the edge. As a result, GO has higher amphiphilicity and reactivity than other nano-materials, thus making it a more suitable nanofiller for improving the properties of hybrid nanofiber membranes than other nanomaterials [23-25]. Recently, it has been found that adding GO nanofillers can greatly enhance the mechanical properties of hybrid nanofiber membranes. However, due to the limitation of dispersibility in the polymer precursor solutions, uniform distribution of excess GO nanofillers over 0.4 wt.\% into nanofibers is still challenging [26]. Therefore, improving the dispersibility of GO in polymer precursor solution has become a hot topic in recent research [25,27-29].

In this report, GO was firstly prepared from flake graphite using an improved Hummer's method. We also modified the surface of GO with a simple method in order to improve its dispersibility. This modified GO was mixed with a PAN polymer solution to form a homogeneous precursor solution. The final precursor solution was then fabricated as the hybrid nanofiber membranes via the electrospinning process. The resulting nanofiber membranes were characterized by scanning electron microscopy (SEM), Fourier-transform infrared spectroscopy (FT-IR), contact angle, thermogravimetric analysis (TGA), and mechanical property.

\section{Materials and Methods}

\subsection{Materials}

Graphite flake (Bay Carbon Inc., Baycity, MI, USA), sodium nitrate $\left(\mathrm{NaNO}_{3}, \geq 99 \%\right.$, Sigma-Aldrich Korea, Seoul, Korea), $\mathrm{KMnO}_{4}$ (99\%, Sigma-Aldrich), sulfuric acid (98\%, Duksan, Seoul, Korea), and hydrogen peroxide $\left(\mathrm{H}_{2} \mathrm{O}_{2}, 35 \%\right.$, Samchen Co., Ltd., Seoul, Korea) were used for the synthesis of GO. Materials used to manufacture the nanofibers were polyacrylonitrile (PAN, Mw 150,000, Sigma-Aldrich) and N,N-dimethyl formamide (DMF, 99.5\%, Duksan). Polydiallyldimethylammonium chloride (PDDA) was used as a surfactant to modify the surface of GO. All chemicals were used without further purification.

\subsection{Synthesis of Graphene Oxide (GO) and Modified GO by Polydiallyldimethylammonium (PDDA) (GP)}

GO was synthesized from graphite using a time-saving improved Hummer's method. Briefly, graphite flake $(2 \mathrm{~g}), \mathrm{NaNO}_{3}(1.52 \mathrm{~g})$, and sulfuric acid (68 $\left.\mathrm{mL}\right)$ were mixed and stirred for $10 \mathrm{~min}$, and then $9 \mathrm{~g}$ of $\mathrm{KMnO}_{4}$ was slowly added into the mixture. The mixture was then allowed to heat to $60^{\circ} \mathrm{C}$ and stirred for $40 \mathrm{~min}$. One hundred milliliters of distilled water (DI water) was added to the solution, followed by mixing for $1 \mathrm{~h}$ at $90^{\circ} \mathrm{C}$ [30]. The temperature of the mixture was decreased to $50^{\circ} \mathrm{C}$, followed by the addition of $100 \mathrm{~mL}$ DI water again. The mixture was then fully dispersed by sonication for $3 \mathrm{~h}$ and then the mixture was filtered using a filter paper (No. 2, Advantec, Dublin, CA, USA). In order to remove the unreacted residue in the filtrate, DI water (180 mL), $\mathrm{H}_{2} \mathrm{O}_{2}(6 \mathrm{~mL})$, and sulfuric acid $(1 \mathrm{~mL})$ were added, respectively, and then the mixed filtrate was centrifuged at $4000 \mathrm{rpm}$ for $30 \mathrm{~min}$ [31]. The filtrate was washed several times with DI water and ethanol, then thoroughly dried in a vacuum oven for $24 \mathrm{~h}$ to obtain the GO product. Dried GO (0.5 g) was fully dispersed in water $(100 \mathrm{~mL})$ for $1 \mathrm{~h}$ by sonication and centrifuged for $30 \mathrm{~min}$. Then, the final GO was obtained by filtering the GO solution and dried in a vacuum oven. The fully dried GO $(0.05 \mathrm{~g})$ was dispersed in DI water (99.95 g) to prepare GO suspension for modification with the help of sonication. PDDA (0.033 g) was 
added to the GO suspension and stirred for $24 \mathrm{~h}$. Finally, the GO + PDDA (GP) was obtained by filtering and vacuum drying.

\subsection{Fabrication of Polyacrylonitrile (PAN) and Graphene Oxide Modified by Polydiallyldimethylammonium} Chloride/Polyacrylonitrile (GP/PAN) Hybrid Nanofiber Membranes via Electrospinning

The PAN nanofiber membranes incorporated with varying amounts of GP were fabricated via the electrospinning method. A homogenous precursor solution of PAN and GP listed in Table 1 was prepared and a series of GP (0-1.0 wt.\%) was initially dispersed in DMF by sonication for $1 \mathrm{~h}$. PAN powder was then added to the above solution and fully dissolved by stirring for $24 \mathrm{~h}$ at $50^{\circ} \mathrm{C}$. Then, the prepared solutions were filled into a $5 \mathrm{~mL}$ syringe with a 23-gauge needle. The syringe was positioned vertically for $30 \mathrm{~min}$ or more to remove the air bubbles. Subsequently, the syringe was installed in an automated syringe pump (KDS100, KD Scientific Korea Inc., Seoul, Korea) to control the ejection speed of the solution, and the voltage supply equipment used was a CPS 60K02VIT (CHUNGPA EMT co., Ltd., Seoul, Korea). Prepared spinning solutions were electrospun on to aluminum foil under an electrical field with optimized voltage $(15 \mathrm{kV})$, flow rate $(0.8 \mathrm{~mL} / \mathrm{h})$, distance between the needle tip and the collector $(15 \mathrm{~cm})$, relative humidity $(20-40 \%)$ and room temperature.

Table 1. Component ratio of polyacrylonitrile (PAN) and graphene oxide modified by polydiallyldimethylammonium chloride/polyacrylonitrile (GP/PAN) electrospinning solution. $(\mathrm{DMF}=$ $\mathrm{N}, \mathrm{N}$-dimethyl formamide).

\begin{tabular}{cccc}
\hline Sample Name & $\begin{array}{c}\text { GP } \\
\text { (wt.\%) }\end{array}$ & $\begin{array}{c}\text { PAN } \\
\text { (wt.\%) }\end{array}$ & $\begin{array}{c}\text { DMF } \\
\text { (wt.\%) }\end{array}$ \\
\hline PAN & 0 & 10 & 90.0 \\
\hline GP01PAN & 0.1 & 10 & 89.9 \\
\hline GP02PAN & 0.2 & 10 & 89.8 \\
\hline GP03PAN & 0.3 & 10 & 89.7 \\
\hline GP04PAN & 0.4 & 10 & 89.6 \\
\hline GP10PAN & 1.0 & 10 & 89.0 \\
\hline
\end{tabular}

2.4. Characterization of Synthesized Graphene Oxide GO and Graphene Oxide Modified by Polydiallyldimethylammonium Chloride/Polyacrylonitrile (GP/P) Hybrid Nanofiber Membranes

The morphological analysis of the GO was carried out by FESEM (Field Emission Scanning Electron Microscope, Hitachi Korea, S-4200, Seoul, Korea). An AFM (Atomic Force Microscope, NanoSurf Korea, Seoul, Korea) was used to analyze the surface morphology of GO. FT-IR (JASCO, FT/IR-620, Tokyo, Japan) was used to observe the various functional groups of synthesized GO. The Raman test was performed on Thermo DXR Raman Spectroscopy (Thermo Fisher Scientific Korea, Seoul, Korea) with a $532 \mathrm{~nm}$ laser and $1-5 \mathrm{~mW}$ power.

The optical image of nanofibers was taken with a Pentax K-S2 DSLR Camera and the structural features of nanofibers were examined by scanning electron microscope (SEM, JSM5410, Tokyo, Japan) after coating with a gold target. The pore diameters of nanofiber membranes were analyzed with a capillary porometer (Porolux 1000, IB-FT GmbH, Berlin, German) under wet and dry conditions using a Porewick standard solution, and the effective diameter of the nanofibers was fixed at $1.9 \mathrm{~cm}$. The porosity of the samples $(5 \mathrm{~cm} \times 5 \mathrm{~cm})$ was examined by measuring the dry and wet weights of the nanofiber membranes after soaking in $\mathrm{n}$-butanol for $1 \mathrm{~h}$. The hydrophilicity of nanofiber membranes was confirmed with a contact angle analyzer (Phoenix 300, SEO Inc, Seoul, Korea) using a water droplet. The mechanical testing was performed using a universal tensometer (MYUNGJI TECH, TENSO, Seoul, Korea) with a crosshead speed of $500 \mathrm{~mm} / \mathrm{min}$ and a sample size of $100 \mathrm{~mm} \times 30 \mathrm{~mm}$. 


\section{Results}

\subsection{Characterization of Synthesized Graphene Oxide (GO)}

The SEM image (Figure 1a) indicates that GO is few micro-meters in length and width. Figure $1 \mathrm{~b}$ shows the AFM image of GO, and the line scan conducted on this sample. Figure 1c shows the height profile of the line scan. The thickness of the synthesized GO is approximately $0.9-1 \mathrm{~nm}$. It is reported that the thickness of perfect single layer of GO was about $0.8 \mathrm{~nm}$. Therefore, we can infer that this synthesized GO is almost a single layer.
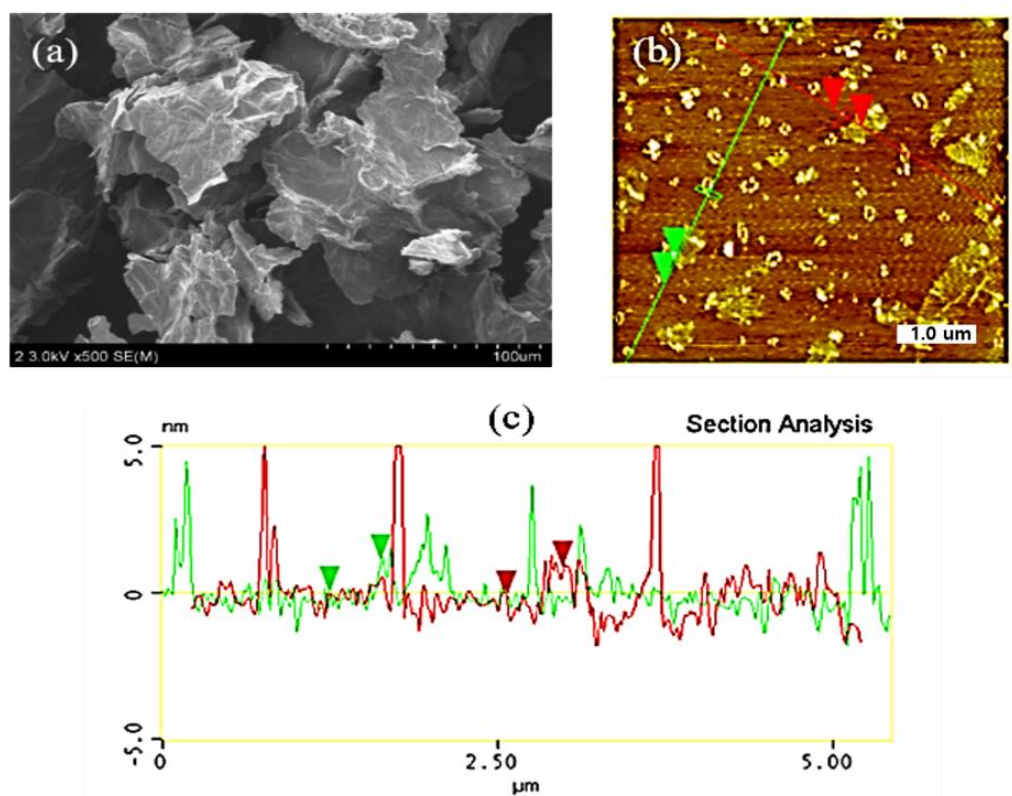

Figure 1. (a) field emission scanning electron microscopy (FESEM) image of graphene oxide (GO),

(b) atomic force microscopy (AFM) image of GO, and (c) height profile of GO.

FT-IR spectra is recognized as an important tool for characterization of functional group in GO, so FT-IR test was performed and the spectra is shown in Figure 2. Among the salient features observed are the bands at $1740 \mathrm{~cm}^{-1}, 1630 \mathrm{~cm}^{-1}, 1226 \mathrm{~cm}^{-1}$, and $1040 \mathrm{~cm}^{-1}$, corresponding to the stretching modes of $\mathrm{C}=\mathrm{O},-\mathrm{C}=\mathrm{C}, \mathrm{C}-\mathrm{O}$, and $\mathrm{C}-\mathrm{O}-\mathrm{C}$ groups in $\mathrm{GO}$, respectively $[32,33]$.

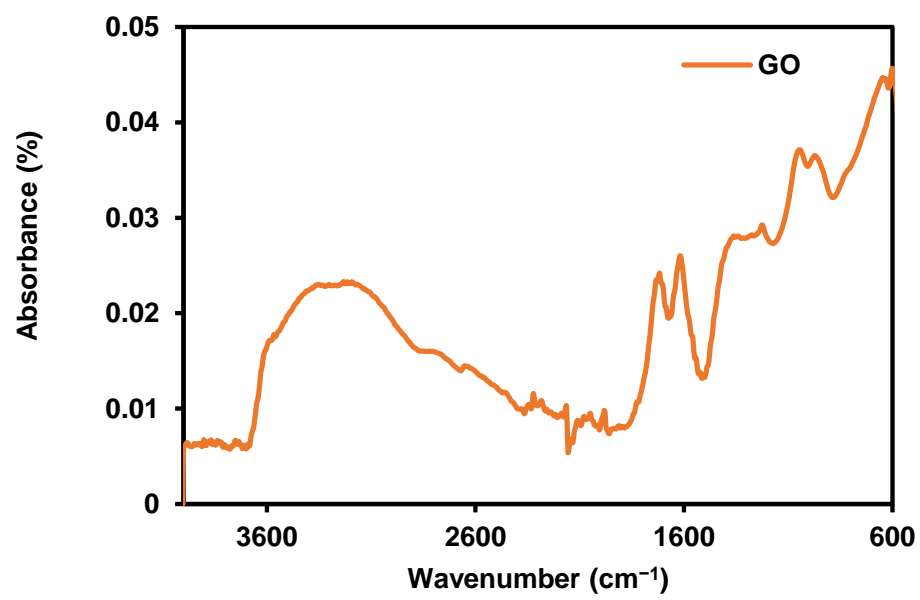

Figure 2. Fourier-transform infrared spectroscopy (FT-IR) of synthesized graphene oxide (GO).

As shown in Figure 3, the Raman spectrum of synthesized GO displays a D-band at $1353 \mathrm{~cm}^{-1}$ and a broad G-band at $1587 \mathrm{~cm}^{-1}$, which were the typical spectra of GO [34]. Ramakrishnan et al. 
reported that the G-band and D-band represented different carbon networks. The G-band was due to the characteristics of all sp2-hybridized carbon networks, resulting in the first-order scattering in the Brillouin zone center, while the D-band, caused by the attachment of oxygen groups on the carbon basal plane, showed the structural imperfections [35].

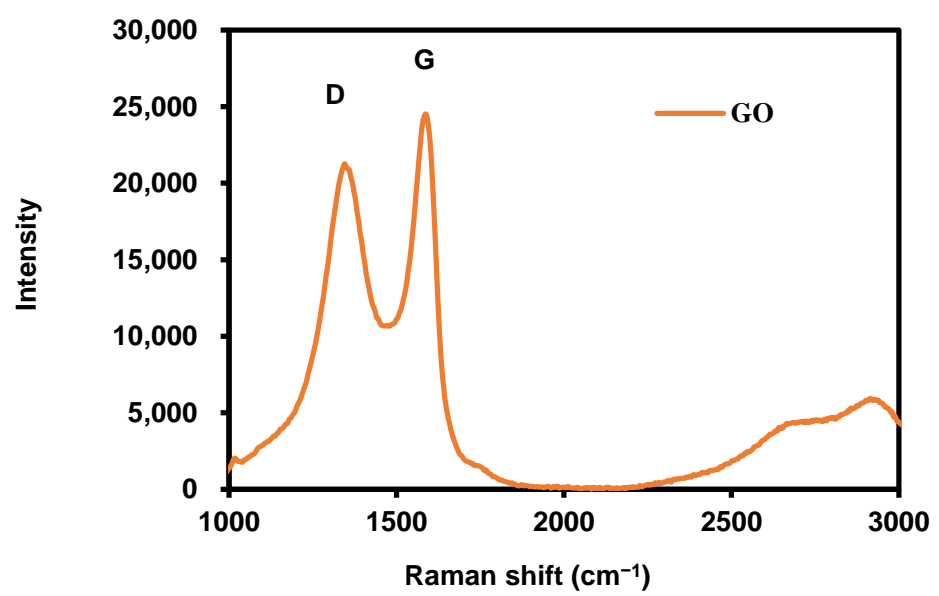

Figure 3. Raman spectra of synthesized graphene oxide (GO).

3.2. Characterization of Graphene Oxide Modified by Polydiallyldimethylammonium Chloride/Polyacrylonitrile (GP/PAN) Hybrid Nanofiber Membranes

Figures 4 and 5 show the digital photos and the SEM images of representative PAN and a series of GP/PAN hybrid nanofiber membranes, respectively. It can be easily observed that the more GP content in the PAN, the darker the color that was obtained [30]. Based on our previous research, the loading amount of bare GO into PAN nanofiber membranes by electrospinning generally reached up to $0.4 \mathrm{wt}$. $\%$ with respect to the polymer concentration, due to the limited dispersity of GO in a polymer precursor solution [26]. Only through the process of simple surface modification, the modified GO (GP) nanofiller was reliably added up to $1.0 \mathrm{wt}$ \% under the same electrospinning conditions. This modification involved the electrostatic interactions between PDDA and GO, which greatly improved the dispersity of GO in polymer precursor solution as well as reliable electrospinning of nanofibers without a needle blocking problem. Meanwhile, as the amount of GP increased, the average diameter of nanofibers increased from $0.563 \mu \mathrm{m}$ to $0.618 \mu \mathrm{m}$. This is reasonable, since as the amount of GP increases in the polymer solution, the viscosity of the final precursor solution increases due to the low amount of solvent, resulting in thicker nanofibers. However, we think that this can only happen if GP is dispersed homogeneously in the polymer solution. Otherwise, the viscosity of the GP polymer solution will not increase consistently. The pore size and thickness of the nanofiber membranes were examined (Table 2). The PAN nanofiber membrane possessed an average pore size of $213.3 \mathrm{~nm}$ and a thickness of $77 \mu \mathrm{m}$. The hybrid nanofiber membranes gradually increased the pore size and the thickness with the increase of the GP content. These results demonstrate our previous research results once more, i.e., as the diameter of nanofibers increases, the pore size and thickness also increase [26]. 
Table 2. Pore size and thickness of polyacrylonitrile (PAN), graphene oxide modified by polydiallyldimethylammonium chloride/polyacrylonitrile (GP/PAN) nanofiber membranes.

\begin{tabular}{ccccc}
\hline $\begin{array}{c}\text { Sample } \\
\text { Name }\end{array}$ & $\begin{array}{c}\text { Biggest Pore Size } \\
(\mathbf{n m})\end{array}$ & $\begin{array}{c}\text { Smallest Pore Size } \\
(\mathbf{n m})\end{array}$ & $\begin{array}{c}\text { Average Pore } \\
\text { Size }(\mathbf{n m})\end{array}$ & Thickness $(\boldsymbol{\mu m})$ \\
\hline PAN & 459.5 & 169.5 & 213.3 & $77 \pm 3$ \\
\hline GP01PAN & 474.2 & 171.2 & 226.3 & $79 \pm 2$ \\
\hline GP02PAN & 484.5 & 175.5 & 232.7 & $81 \pm 2$ \\
\hline GP03PAN & 473.3 & 183.2 & 243.5 & $83 \pm 3$ \\
\hline GP04PAN & 482.2 & 194.3 & 245.5 & $84 \pm 2$ \\
\hline GP10PAN & 485.5 & 243.6 & 269.3 & $88 \pm 3$ \\
\hline
\end{tabular}

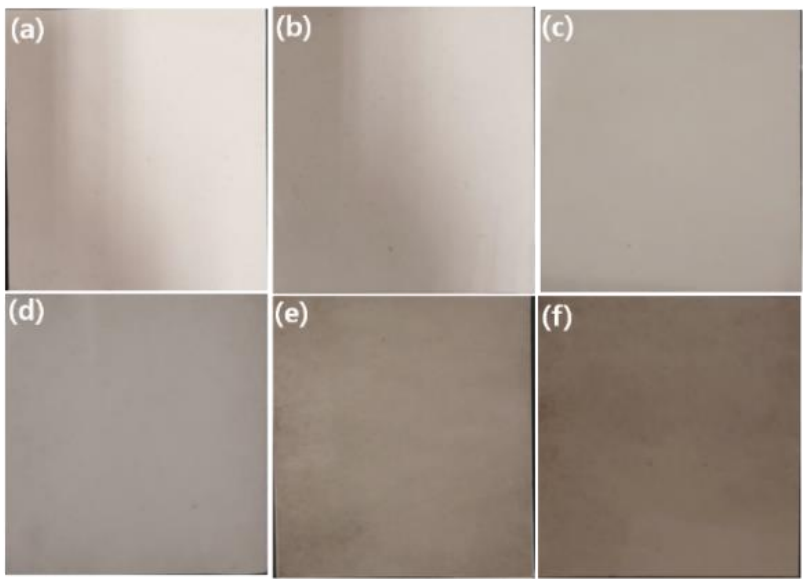

Figure 4. Digital photos of polyacrylonitrile (PAN), graphene oxide modified by polydiallyldimethylammonium chloride/polyacrylonitrile (GP/PAN) hybrid nanofiber membranes; (a) PAN nanofiber membrane, (b) GP01PAN, (c) GP02PAN, (d) GP03PAN, (e) GP04PAN, (f) GP10PAN.

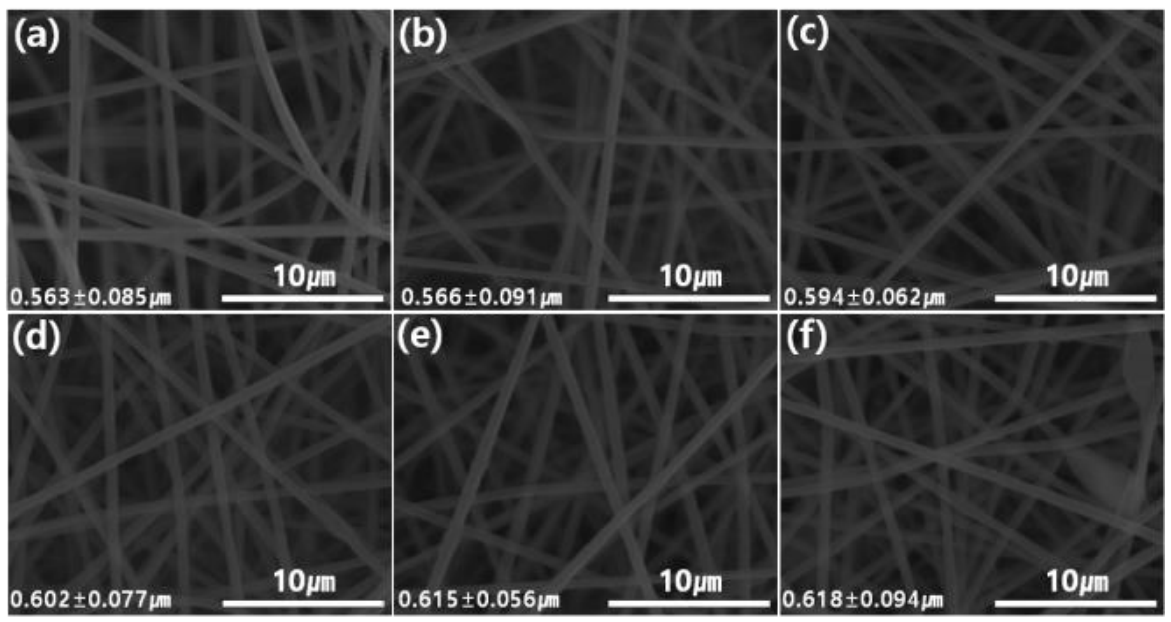

Figure 5. Scanning electron microscopy (SEM) images of polyacrylonitrile (PAN), graphene oxide modified by polydiallyldimethylammonium chloride/polyacrylonitrile (GP/PAN) hybrid nanofiber membranes; (a) PAN nanofiber membrane, (b) GP01PAN, (c) GP02PAN, (d) GP03PAN, (e) GP04PAN, (f) GP10PAN.

To confirm the successful composite of GP into the nanofibers, the FT-IR of GP/PAN nanofibers were measured (Figure 6). It was easily recognized that GP was successfully added, due to the 
stronger specific GO functional group peaks (3200 cm $\mathrm{cm}^{-1}\left(\mathrm{OH}\right.$ peak), $1740 \mathrm{~cm}^{-1}(\mathrm{C}=\mathrm{O}), 1630 \mathrm{~cm}^{-1}$ $\left.(\mathrm{C}=\mathrm{C}), 1226 \mathrm{~cm}^{-1}(\mathrm{C}-\mathrm{O}), 1040 \mathrm{~cm}^{-1}(\mathrm{C}-\mathrm{O}-\mathrm{C})\right)$ in the FT-IR spectra [36,37]. Also, in Figure 7 , the contact angle results display an obvious decrease trend due to the various hydrophilic functional groups in the GO, which have also been checked in the FT-IR and some earlier published work [36,38].

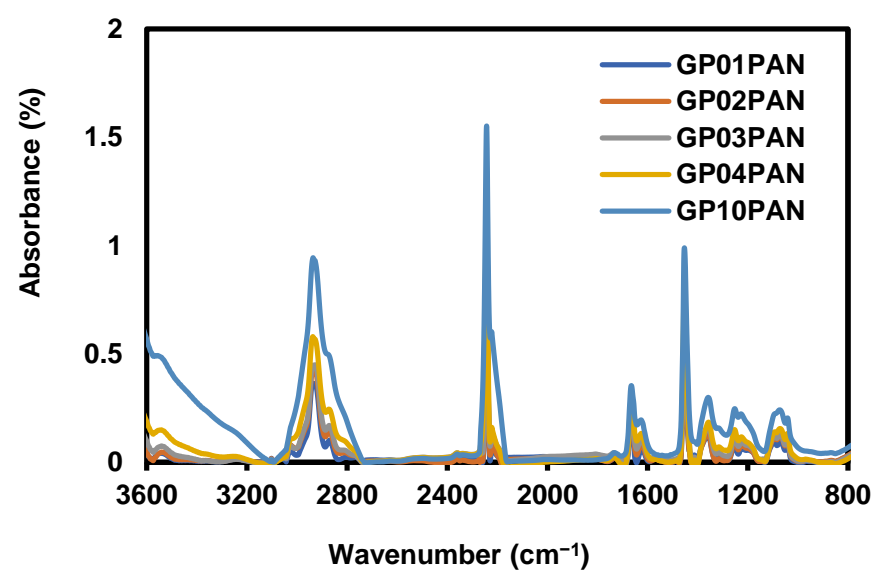

Figure 6. Fourier-transform infrared spectroscopy (FT-IR) spectra of graphene oxide modified by polydiallyldimethylammonium chloride/polyacrylonitrile (GP/PAN) hybrid nanofiber membranes.

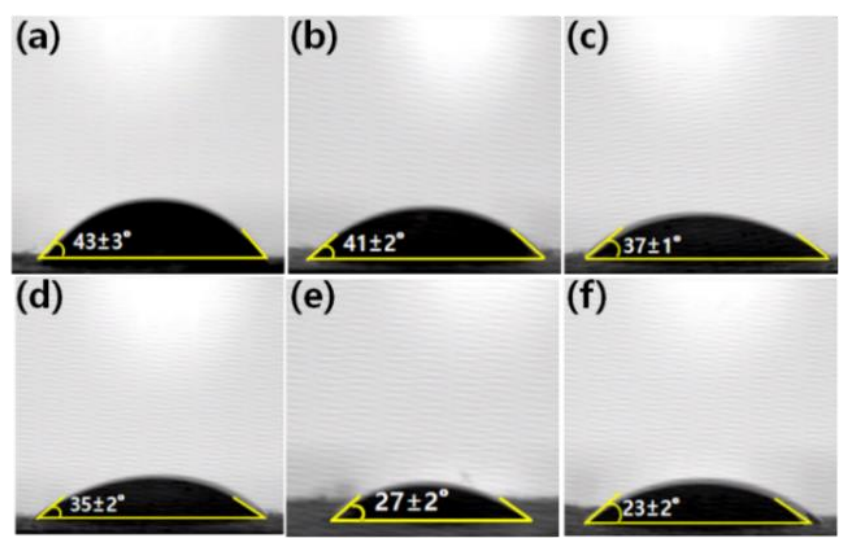

Figure 7. Contact angle of polyacrylonitrile (PAN), graphene oxide modified by polydiallyldimethylammonium chloride/polyacrylonitrile (GP/PAN) hybrid nanofiber membranes;

(a) PAN nanofiber membrane, (b) GP01PAN, (c) GP02PAN, (d) GP03PAN, (e) GP04PAN, (f) GP10PAN.

The thermal stability of the PAN nanofiber membrane and GP/PAN hybrid nanofiber membranes is shown in Figure 8. Only two samples were measured. Under pyrolytic conditions, the PAN nanofiber membrane with and without nanofillers degraded in two steps. Compared with the PAN nanofiber membrane, the onset thermal decomposition temperature was increased from $300{ }^{\circ} \mathrm{C}$ to $340{ }^{\circ} \mathrm{C}$. It could thus be concluded that with the addition of GP, the thermal stability of the nanofiber membrane increased. The noticeable improvement of the thermal stability could be contributed to both the original property of GO and the surface modified with PDDA. 


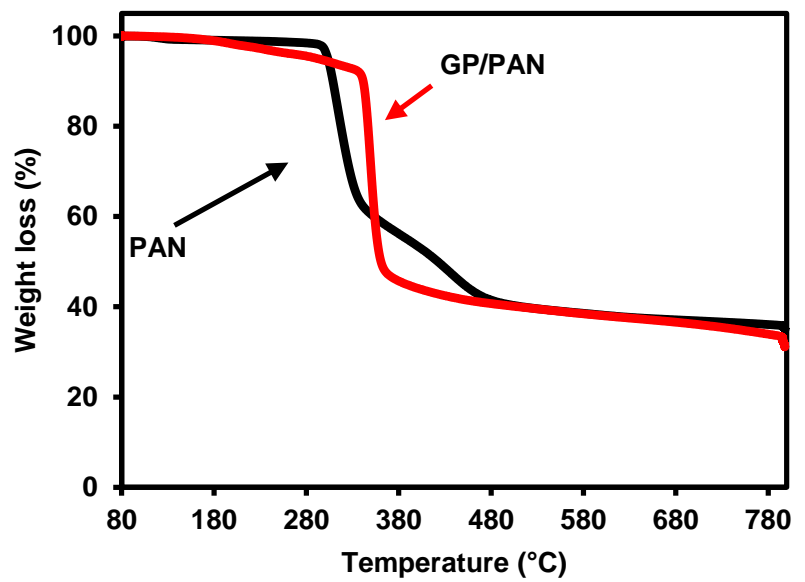

Figure 8. Thermogravimetric curves of polyacrylonitrile (PAN) and graphene oxide modified by polydiallyldimethylammonium chloride/polyacrylonitrile (GP10/PAN) hybrid nanofiber membranes.

Figure 9 shows the stress-strain curves of the PAN nanofiber membrane and series of the GP/PAN hybrid nanofiber membranes. Overall, the tensile strength of all hybrid nanofiber membranes had obviously improved, compared to the PAN nanofiber membrane. However, when the GP content increased to $>0.4 \mathrm{wt} . \%$, the hybrid nanofiber membrane appeared to have a little lower stress, due to the reduction of the dispersion. When the GP content is more than $0.4 \mathrm{wt} . \%$, it will be difficult to disperse uniformly in the PAN precursor solutions. Consequently, the beaded structures will be formed in the hybrid nanofiber membrane, which can also be confirmed in the SEM images of Figure 5f [26,37].

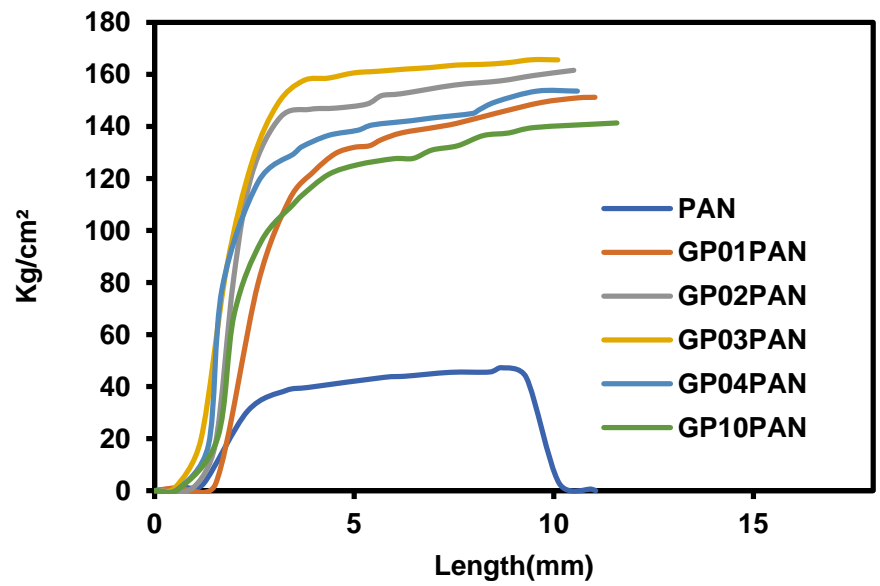

Figure 9. Tensile strength of polyacrylonitrile (PAN) nanofiber and graphene oxide modified by polydiallyldimethylammonium chloride/polyacrylonitrile (GP/PAN) hybrid nanofibers.

\section{Conclusions}

In this work, we focused on the improvement of GO's dispersity in a PAN precursor solution for electrospinning and the fabrication of GP/PAN (GP: GO modified by PDDA) hybrid nanofiber membranes. To the best of our knowledge, according to the simple surface modification, the GO content in the polymer precursor solution can be added more than $0.4 \mathrm{wt} . \%$ (up to $1.0 \mathrm{wt} . \%$ ) under the same electrospinning conditions for the first time. The prepared GO nanomaterials and hybrid nanofiber membranes were characterized by SEM, FT-IR, Raman spectra, contact angle, thermal and physical properties, etc. These results showed that the pore size and the thickness can be easily controlled by the content of GP. According to contact angle analysis, these fabricated PAN/GP hybrid nanofiber membranes exhibited better hydrophilic characteristics than the PAN nanofiber membrane. Lastly, the incorporation of the GP into the PAN nanofiber membranes generally improved their thermal 
stability and mechanical properties, compared to the PAN nanofiber membrane. Based on all the above results and the original advantage of nanofibers, the PAN/GP hybrid nanofiber membranes could be a promising candidate for water treatment membranes. Further research about water purification and battery performance is being investigated.

Author Contributions: The experiments were conceptualized by J.H. and J.Y. performed the experiments. J.H. analyzed the data. J.H. and H.B. wrote the manuscript.

Funding: This research is supported by the National Research Foundation of Korea Grant funded by the Korean Government (NRF-2018R1A2B6008854).

Conflicts of Interest: The authors declare no conflict of interest.

\section{References}

1. MacDiarmid, A.G.; Jones, W.E., Jr.; Norris, I.D.; Gao, J.; Johnson, A.T., Jr.; Pinto, N.J.; Hone, J.; Han, B.; Ko, F.K.; Okuzaki, H.; et al. Electrostatically-generated nanofibers of electronic polymers. Synth. Met. 2001, 119, 27-30. [CrossRef]

2. Huang, Z.M.; Zhang, Y.Z.; Kotaki, M.; Ramakrishna, S. A review on polymer nanofibers by electrospinning and their applications in nanocomposites. Compos. Sci. Technol. 2003, 63, 2223-2253. [CrossRef]

3. Jacangelo, J.G.; Trussell, R.R.; Watson, M. Role of membrane technology in drinking water treatment in the United States. Desalination 1997, 113, 119-127. [CrossRef]

4. Martin, C.R. Membrane-Based Synthesis of Nanomaterials. Chem. Mater. 1996, 8, 1739-1746. [CrossRef]

5. Ma, P.X.; Zhang, R. Synthetic nano-scale fibrous extracellular matrix. J. Biomed. Mater. Res. 1999, 46, 60-72. [CrossRef]

6. Whitesides, G.M.; Grzybowski, B. Self-assembly at all scales. Science 2002, 295, 2418-2421. [CrossRef] [PubMed]

7. Yoon, K.; Hsiao, B.S.; Chu, B. Functional nanofibers for environmental applications. J. Mater. Chem. 2008, 18, 5326-5334. [CrossRef]

8. Lu, X.; Wang, C.; Wei, Y. One-dimensional composite nanomaterials: Synthesis by electrospinning and their applications. Small 2009, 5, 2349-2370. [CrossRef]

9. Greiner, A.; Wendorff, J.H. Electrospinning: A fascinating method for the preparation of ultrathin fibers. Angew. Chem. Int. Ed. Engl. 2007, 46, 5670-5703. [CrossRef]

10. Lannutti, J.; Reneker, D.; Ma, T.; Tomasko, D.; Farson, D. Electrospinning for tissue engineering scaffolds. Mater. Sci. Eng. C 2007, 27, 504-509. [CrossRef]

11. Lee, S.; Kay Obendorf, S. Use of Electrospun Nanofiber Web for Protective Textile Materials as Barriers to Liquid Penetration. Text. Res. J. 2007, 77, 696-702. [CrossRef]

12. Lee, S.H.; Ku, B.C.; Wang, X. Design, Synthesis and Electrospinning of a Novel Fluorescent Polymer for Optical Sensor Applications. Mater. Res. Soc. Symp. Proc. 2002, 708, 403-408. [CrossRef]

13. Subbiah, T.; Bhat, G.S.; Tock, R.W.; Parameswaran, S.; Ramkumar, S.S. Electrospinning of Nanofibers. J. Appl. Polym. Sci. 2005, 96, 557-569. [CrossRef]

14. Ahire, J.J.; Neveling, D.P.; Dicks, L.M.T. Polyacrylonitrile (PAN) nanofibres spun with copper nanoparticles: An anti-Escherichia coli membrane for water treatment. Appl. Microbiol. Biotechnol. 2018, 102, 7171-7181. [CrossRef] [PubMed]

15. Dabirian, F.; Hosseini Ravandi, S.A.; Hashemi Sanatgar, R.; Hinestroza, J.P. Manufacturing of twisted continuous PAN nanofiber yarn by electrospinning process. Fibers Polym. 2011, 12, 610-615. [CrossRef]

16. He, J.H.; Wan, Y.Q.; Yu, J.Y. Effect of concentration on electrospun polyacrylonitrile (PAN) nanofibers. Fibers Polym. 2008, 9, 140-142. [CrossRef]

17. Hou, C.; Yang, H.; Xu, Z.-L.; Wei, Y. Preparation of PAN/PAMAM blend nanofiber mats as efficient adsorbent for dye removal. Fibers Polym. 2015, 16, 1917-1924. [CrossRef]

18. Wu, M.; Wang, Q.; Li, K.; Wu, Y.; Liu, H. Optimization of stabilization conditions for electrospun polyacrylonitrile nanofibers. Polym. Degrad. Stab. 2012, 97, 1511-1519. [CrossRef]

19. Wang, T.; Kumar, S. Electrospinning of polyacrylonitrile nanofibers. J. Appl. Polym. Sci. 2006, 102, 1023-1029. [CrossRef] 
20. Hosseini Ravandi, S.A.; Mehrara, S.; Sadrjahani, M.; Khodaparast Haghi, A. Tunable wicking behavior via titanium oxide embedded in polyacrylonitrile nanofiber strings of yarn. Polym. Bull. 2019. [CrossRef]

21. Kancheva, M.; Toncheva, A.; Paneva, D.; Manolova, N.; Rashkov, I.; Markova, N. Materials from Nanosized ZnO and Polyacrylonitrile: Properties Depending on the Design of Fibers (Electrospinning or Electrospinning/Electrospraying). J. Inorg. Organomet. Polym. 2017, 27, 912-922. [CrossRef]

22. Yar, A.; Haspulat, B.; Üstün, T.; Eskizeybek, V.; Avc1, A.; Kamış, H. Achour, S., Electrospun TiO $2 / \mathrm{ZnO} / \mathrm{PAN}$ hybrid nanofiber membranes with efficient photocatalytic activity. RSC Adv. 2017, 7, 29806-29814. [CrossRef]

23. Wang, C.; Li, Y.; Ding, G.; Xie, X.; Jiang, M. Preparation and characterization of graphene oxide/poly(vinyl alcohol) composite nanofibers via electrospinning. J. Appl. Polym. Sci. 2013, 127, 3026-3032. [CrossRef]

24. Cassagneau, T.; Guerin, F.; Fendler, J.H. Preparation and Characterization of Ultrathin Films Layer-by-Layer Self-Assembled from Graphite Oxide Nanoplatelets and Polymers. Langmuir 2000, 16, 7318-7324. [CrossRef]

25. Hou, H.; Hu, X.; Liu, X.; Hu, W.; Meng, R.; Li, L. Sulfonated graphene oxide with improved ionic performances. Ionics 2015, 21, 1919-1923. [CrossRef]

26. Lee, J.; Yoon, J.; Kim, J.H.; Lee, T.; Byun, H. Electrospun PAN-GO composite nanofibers as water purification membranes. J. Appl. Polym. Sci. 2017, 135, 45858-45866. [CrossRef]

27. Stankovich, S.; Piner, R.D.; Nguyen, S.; Ruoff, R.S. Synthesis and exfoliation of isocyanate-treated graphene oxide nanoplatelets. Carbon 2006, 44, 3342-3347. [CrossRef]

28. Compton, O.C.; Dikin, D.A.; Putz, K.W.; Brinson, L.C.; Nguyen, S.T. Electrically Conductive "Alkylated" Graphene Paper via Chemical Reduction of Amine-Functionalized Graphene Oxide Paper. Adv. Mater. 2010, 22, 892-896. [CrossRef]

29. Pierini, F.; Lanzi, M.; Nakielski, P.; Pawłowska, S.; Zembrzycki, K.; Kowalewski, T.A. Electrospun poly(3-hexylthiophene)/poly(ethylene oxide)/graphene oxide composite nanofibers: Effects of graphene oxide reduction. Polym. Adv. Technol. 2016, 27, 1465-1475. [CrossRef]

30. Jang, W.; Yun, J.; Jeon, K.; Byun, H. PVdF/graphene oxide hybrid membranes via electrospinning for water treatment applications. RSC Adv. 2015, 5, 46711-46717. [CrossRef]

31. Jang, W.; Yun, J.; Byun, H. Preparation of PAN Nanofiber Composite Membrane with $\mathrm{Fe}_{3} \mathrm{O}_{4}$ Functionalized Graphene Oxide and its Application as a Water Treatment Membrane. Membr. J. 2014, 24, 151-157. [CrossRef]

32. Wang, Q.; Du, Y.; Feng, Q.; Huang, F.; Lu, K.; Liu, J.; Wei, Q. Nanostructures and surface nanomechanical properties of polyacrylonitrile/graphene oxide composite nanofibers by electrospinning. J. Appl. Polym. Sci. 2013, 128, 1152-1157. [CrossRef]

33. Ke, H.; Pang, Z.; Xu, Y.; Chen, X.; Fu, J.; Cai, Y.; Huang, F.; Wei, Q. Graphene oxide improved thermal and mechanical properties of electrospun methyl stearate/polyacrylonitrile form-stable phase change composite nanofibers. J. Therm. Anal. Calorim. 2014, 117, 109-122. [CrossRef]

34. Hu, M.; Mi, B. Enabling Graphene Oxide Nanosheets as Water Separation Membranes. Environ. Sci. Technol. 2013, 47, 3715-3723. [CrossRef] [PubMed]

35. Ramakrishnan, S.; Dhakshnamoorthy, M.; Jelmy, E.J.; Vasanthakumari, R.; Kothurkar, N.K. Synthesis and characterization of graphene oxide-polyimide nanofiber composites. RSC Adv. 2014, 4, 9743-9749. [CrossRef]

36. Park, Y.H.; Nam, S.Y. Characterization of Water Treatment Membrane Using Various Hydrophilic Coating Materials. Membr. J. 2017, 27, 60-67. [CrossRef]

37. Chen, J.; Yao, B.; Li, C.; Shi, G.Q. An improved Hummers method for eco-friendly synthesis of graphene oxide. Carbon 2013, 64, 225-229. [CrossRef]

38. Tan, C.; Huang, X.; Zhang, H. Synthesis and applications of graphene-based noble metal nanostructures. Mater. Today 2013, 16, 29-36. [CrossRef]

(C) 2019 by the authors. Licensee MDPI, Basel, Switzerland. This article is an open access article distributed under the terms and conditions of the Creative Commons Attribution (CC BY) license (http://creativecommons.org/licenses/by/4.0/). 